\title{
Poly(Thionine)-Modified Screen-Printed Electrodes for CA 19-9 Detection and Its Properties in Raman Spectroscopy
}

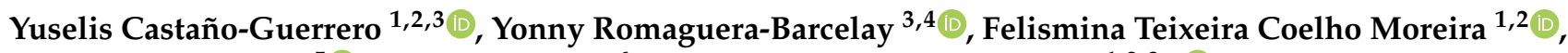 \\ Walter Ricardo Brito ${ }^{5}\left(\mathbb{D}\right.$, Elvira Fortunato ${ }^{6}$ and Maria Goreti Ferreira Sales $1,2,3, *(\mathbb{C})$ \\ 1 Instituto Superior de Engenharia do Porto, Rua Dr. António Bernardino de Almeida, 431, \\ 4249-015 Porto, Portugal; yuscg@isep.ipp.pt (Y.C.-G.); ftm@isep.ipp.pt (F.T.C.M.) \\ 2 Centre of Biological Engineering, University of Minho, 4710-057 Braga, Portugal \\ 3 BioMark@UC, Faculty of Sciences and Technology, University of Coimbra, 3030-790 Coimbra, Portugal; \\ yonny.barcelay@uc.pt \\ 4 Department of Physics, Federal University of Amazonas, Manaus 69067005, AM, Brazil \\ 5 LABEL, Department of Chemistry, Federal University of Amazonas, Manaus 69067005, AM, Brazil; \\ wrbrito@ufam.edu.br \\ 6 CENIMAT I i3N, Department of Materials Science, School of Science and Technology, NOVA University of \\ Lisbon and CEMOP/UNINOVA, Campus de Caparica, 2829-516 Caparica, Portugal; emf@fct.unl.pt \\ * Correspondence: goreti.sales@eq.uc.pt
}

Citation: Castaño-Guerrero, Y.; Romaguera-Barcelay, Y.; Moreira, F.T.C.; Brito, W.R.; Fortunato, E.; Sales, M.G.F. Poly(Thionine)Modified Screen-Printed Electrodes for CA 19-9 Detection and Its Properties in Raman Spectroscopy. Chemosensors 2022, 10, 92.

https://doi.org/10.3390/

chemosensors10030092

Academic Editors: Natércia Martins and Sara Fateixa

Received: 29 December 2021 Accepted: 23 February 2022 Published: 27 February 2022

Publisher's Note: MDPI stays neutral with regard to jurisdictional claims in published maps and institutional affiliations.

Copyright: (C) 2022 by the authors. Licensee MDPI, Basel, Switzerland. This article is an open access article distributed under the terms and conditions of the Creative Commons Attribution (CC BY) license (https:// creativecommons.org/licenses/by/ $4.0 /)$.

\begin{abstract}
Polythionine (PTH) is an electroactive compound known for its excellent electron transfer capacity. It has stable and redox centers in its structure, and it can also be generated by electropolymerization of thionine (TH). Due to its properties, it has been used in a large number of applications, including the construction of electrochemical biosensors. In this work, PTH is explored for its ability to generate electrons, which allows it to act as an electrochemical probe in a biosensor that detects CA 19-9 on two different substrates, carbon and gold, using differential pulse voltammetry (DPV) as a reading technique in phosphate buffer $(\mathrm{PhB})$. The analytical features of the resulting electrodes are given, showing linear ranges from 0.010 to $10 \mathrm{U} / \mathrm{mL}$. The Raman spectra of PTH films on gold (substrates or nanostars) and carbon (substrates) are also presented and discussed as a potential use for SERS readings as complementary information to electrochemical data.
\end{abstract}

Keywords: thionine; SERS; electrochemistry; screen-printed electrodes; CA 19-9; cancer biomarker

\section{Introduction}

The use of conventional electrodes has evolved through several designs and one of the most used is based on chemically modified electrodes (CMEs). A CME is a necessary approach to solving sensitivity problems in the detection of analytes that are chemically similar [1]. The literature reports many examples of electrodes modified with nanomaterials [2] and molecules [3,4] such as multiwall carbon nanotubes (MWCNTs) [5], carboxylic acid [6], poly(glutamic acid) [7], penicillamine [8], titanium oxide [9], and others [1], selected according to the intended need.

The possibility of creating polymeric structures in situ to generate CMEs is currently finding wide interest, also in (bio)sensors with electrochemical detection. A wide range of polymers may be produced by electropolymerization, as long as electrical conditions that enable the formation of radical species at the electrode surface are applied to the electrochemical system. The resulting polymers formed at the electrode surface change the electrical features of the receptor surface, which becomes either more conductive or more insolating. The resulting polymers may also display electroactive features, signaling the presence of the polymer.

Polythionine $(\mathrm{PTH})$ is among such polymers. It has received considerable attention as a polymeric film for sensing purposes, yielding improved sensitivity and lower limits 
of detection [1]. Thionine (TH) is its monomeric species, which is a redox dye that has been extensively studied (de Sousa et al., 2018). PTH-modified electrodes have been prepared in a simple way by cyclic voltammetry (CV) having a solution of $\mathrm{TH}$ under a potential sweep in the range from -0.4 to $+0.4 \mathrm{~V}$ [10]; the specific potential range of interest depends on the electrical features of the receptor substrate. They may also be obtained by chronoamperometry, in which a constant oxidation potential is applied for a given time [11]. Overall, it has been accepted that the most probable mechanism for the electropolymerization of phenothiazine derivatives is the bond between the nitrogen atom of the amine group and the atom of the phenothiazine ring [12].

Still, the final electrochemical stability of the PTH-modified electrodes is very critical in sensing and depends greatly on the medium in which $\mathrm{TH}$ solutions arere prepared (ionic content, type of ionic species, and $\mathrm{pH}$ ) and the electrochemical conditions applied. While PTH films prepared by applying constant positive voltage in $0.05 \mathrm{M} \mathrm{H}_{2} \mathrm{SO}_{4}$ are not stable when evaluated in a neutral medium, those prepared in two oxidation steps of constant potential and cyclic scanning in neutral phosphate buffer are stable [1]. In turn, Ferreira et al. conducted electrochemical characterization studies of PTH films produced by different scanning speeds and variations in the number of potential cycles. They concluded that the electroactivity and stability of the resulting PTH are $\mathrm{pH}$-dependent. In a wide range of $\mathrm{pH}$ values, 1.3 to 9 , the authors demonstrated that when increasing the $\mathrm{pH}$ to more alkaline media, a lower electroactivity is observed that is associated with the loss of electroactive sites. In other words, the transfer of electrons between neighboring sites is lower at more alkaline $\mathrm{pH}$ [13]. Yang et al. presented what may be called a hybrid approach to prepare PTH-modified electrodes [11], by using two steps of constant oxidation potential and scanning of the cyclic potential in neutral phosphate solution. The authors referred to two electropolymerization steps when, first, they subjected the electrode to a fixed potential for a few minutes, and as the second step, voltametric cycles in a potential range with a constant sweep. Gao et al. modified screen-printed carbon electrodes (C-SPE) with PTH to determine the oxidation of nicotinamide adenine dinucleotide (NADH) [14]. The electropolymerization was conducted in $\mathrm{PhB} \mathrm{pH} 7.0$ with 25 scanning cycles. The authors considered that $25 \mathrm{CV}$ cycles were adequate to control the electroactive residues in the PTH films. Considering the intended application of this work, the use of screen-printed electrodes (SPEs) as substrates allowed the production of a simple, inexpensive, and versatile analytical approach for monitoring NADH. Overall, there are different electrochemical routes and chemical conditions for preparing PTH, which must be selected appropriately according to the electrochemical system employed.

Thus, this work was directed to the use of PTH as a polymeric material assembled in-situ in SPE substrates. SPEs used herein had carbon or gold substrates on the working electrode, as commercially available. PTH was used to tailor molecularly imprinted polymers (MIPs) for a relevant biomarker protein, which act as biomimetic materials for antibodies. TH acted not only as a functional monomer assembling the MIP materials, but also as an indicator of the electrochemical signal, posing the possibility of having the electrochemical reading of the SPE self-indicated and label-free. This concept was explored for targeting cancer antigen 19-9 (CA 19-9), a cancer biomarker in pancreatic cancer.

Thus, this work described the electropolymerization of $\mathrm{TH}$ in neutral $\mathrm{PhB}$ in the presence of CA 19-9 to generate imprinted cavities in a molecular dimension within the polymeric network. Readings were made in PhB and CA 19-9 binding was followed by differential pulse voltammetry (DPV), as it allowed the measurement of the concentration of specific electroactive species. The resulting structure of PTH was evaluated using Raman spectroscopy, along with a control material prepared in the absence of CA 19-9 and gold nanostars modified with $\mathrm{TH}$. 


\section{Experimental Section}

\subsection{Equipment}

The electrochemical measurements were performed in the potentiostat/galvanostat from Metrohm Autolab (Ultrecht, The Netherlands). The C-SPE and Au-SPE were from DropSens (Oviedo, Spain) (DRP-C110, DPR-250AT). The potentiostat interconnected with SPEs through a box was obtained from BioTID (Oviedo, Spain), Portugal. Raman spectra were collected in a Thermo Scientific DXR Raman Microscope (Madison, WI, USA) with a laser of 532 or $785 \mathrm{~nm}$ operated at a $5 \mathrm{~mW}$ power and a confocal microscope with a $50 \times$ objective lens. The parameters of the observed Raman modes (frequency, line width, and amplitude) were obtained, using Igor software, from the best fit of a sum of damped oscillator functions [15].

\subsection{Reagents and Solutions}

All chemicals were of analytical grade and water ultrapure Milli-Q laboratory grade. Sodium phosphate dibasic dihydrate $\left(\mathrm{Na}_{2} \mathrm{HPO}_{4}\right)$ and ortho-phosphoric acid $85 \%\left(\mathrm{H}_{3} \mathrm{PO}_{4}\right)$ were obtained from Riedel-de-Häen (Charlotte, NC, USA); carbohydrate antigen (CA) 19-9 (250 KU) (Biorbyt, Cambridge, UK) from human metastatic liver carcinoma was obtained from Biorbyt; sodium phosphate dibasic dihydrate, $99.5 \%\left(\mathrm{Na}_{2} \mathrm{HPO}_{4} \cdot 2 \mathrm{H}_{2} \mathrm{O}\right)$ was from Panreac (Barcelona, Spain); sodium dihydrogen phosphate dehydrate $\left(\mathrm{NaH}_{2} \mathrm{PO}_{4} \cdot 2 \mathrm{H}_{2} \mathrm{O}\right)$ was from Scharlau (Pamplona, Spain); sulfuric acid $\left(\mathrm{H}_{2} \mathrm{SO}_{4}\right)$ was obtained from BDH (Dubai, UAE); thionin acetate (TH) from Acros Organics (Geel, Belgium); oxalic acid dihydrate (126.27 g/mol) was obtained from Merck (Branchburg, NJ, USA).

\subsection{SERS Measurements}

The synthesis of gold nanostars (AuNS) was performed according to Castaño-Guerrero et al. 2021. [16]. Briefly, the first step consisted of the production of Au seeds. These were prepared with a solution of $0.5 \mathrm{mM}$ of $\mathrm{HAuCl}_{4}$, and $10 \mathrm{~mL}$ of $1 \%$ citrate solution was added under stirring. To the resulting solution, $10 \mathrm{~mL}$ of PVP $(2.5 \mathrm{mM})$ was added and left under stirring overnight to form Au seeds. The Au seeds obtained were centrifuged (4500 rpm, $45 \mathrm{~min}$ ) and concentrated to $1.5 \mathrm{mM}$.

The AuNS were prepared with a solution with $1.5 \mathrm{~g}$ of PVP $(2.5 \mathrm{mM})$ in $15 \mathrm{~mL}$ of N,NDimethylformamide (DMF) and sonicated. To this solution, $40 \mu \mathrm{L}$ of $\mathrm{HAuCl}_{4}(101 \mathrm{mM})$ was added, followed by the addition of $320 \mu \mathrm{L}$ of the Au seeds $(1.5 \mathrm{mM})$. After $1 \mathrm{~h}$ of stirring, the solution was centrifuged to remove the excess of PVP, using three cycles of centrifugation-dispersion with ethanol (3500 rpm, $40 \mathrm{~min})$. The resulting AuNS was stored at $4{ }^{\circ} \mathrm{C}$ until use.

The Raman probe (AuNS/TH) was set-up with a TH solution $\left(1.0 \times 10^{-3} \mathrm{M}\right)$ in absolute ethanol mixed with the AuNS (0.6 mM) solution, in a 1:1 ratio, and shaken for $1 \mathrm{~h}$, at $25^{\circ} \mathrm{C}$. The resulting solution was centrifuged at $4500 \mathrm{rpm}$ for $20 \mathrm{~min}$ at $25^{\circ} \mathrm{C}$ to remove the excess of unbound TH. The Raman probe AuNS/TH was incubated until dry on the Au-SPE.

\subsection{MIP Assembly for CA 19-9}

The electropolymerization of TH was made on C-SPE or Au-SPE (Figure 1) to generate MIP films for CA 19-9. These films were assembled in several steps. First, SPEs underwent a cleaning stage by exposing the 3-electrode system to a $\mathrm{H}_{2} \mathrm{SO}_{4}$ solution $(0.5 \mathrm{M})$, following 15 cycles of a cyclic voltammetry $(\mathrm{CV})$ procedure, between -0.2 and $1.2 \mathrm{~V}$, at a scan rate of $0.05 \mathrm{~V} / \mathrm{s}$. Then, the C-SPEs were modified by incubating a TH solution $\left(10^{-3} \mathrm{M}\right)$ on the working electrode, for $1 \mathrm{~h}$. The Au-SPEs were electrochemically modified by CV cycling of the same solution, under the potential range from -0.4 to $1.2 \mathrm{~V}$, at a scan rate of $0.05 \mathrm{~V} / \mathrm{s}$. The electropolymerization of TH for generating the MIP material was the following step. To this end, the TH solution $\left(10^{-3} \mathrm{M}\right)$ was mixed with CA 19-9 (1 KU) and incubated on the 3-electrode system, to undergo $15 \mathrm{CV}$ cycles, from -0.4 to $0.4 \mathrm{~V}$ (C-SPE) or -0.4 to $1.2 \mathrm{~V}$ (Au-SPE), at scan rate of $0.05 \mathrm{~V} / \mathrm{s}$. Finally, the template was removed by incubating 
the working electrode in oxalic acid $(0.5 \mathrm{M})$ for $1 \mathrm{~h}$. The same steps were followed in the construction of the control nonimprinted polymer (NIP), in which CA 19-9 was excluded from the procedure. Each step of the MIP/NIP assembly was followed by DPV.

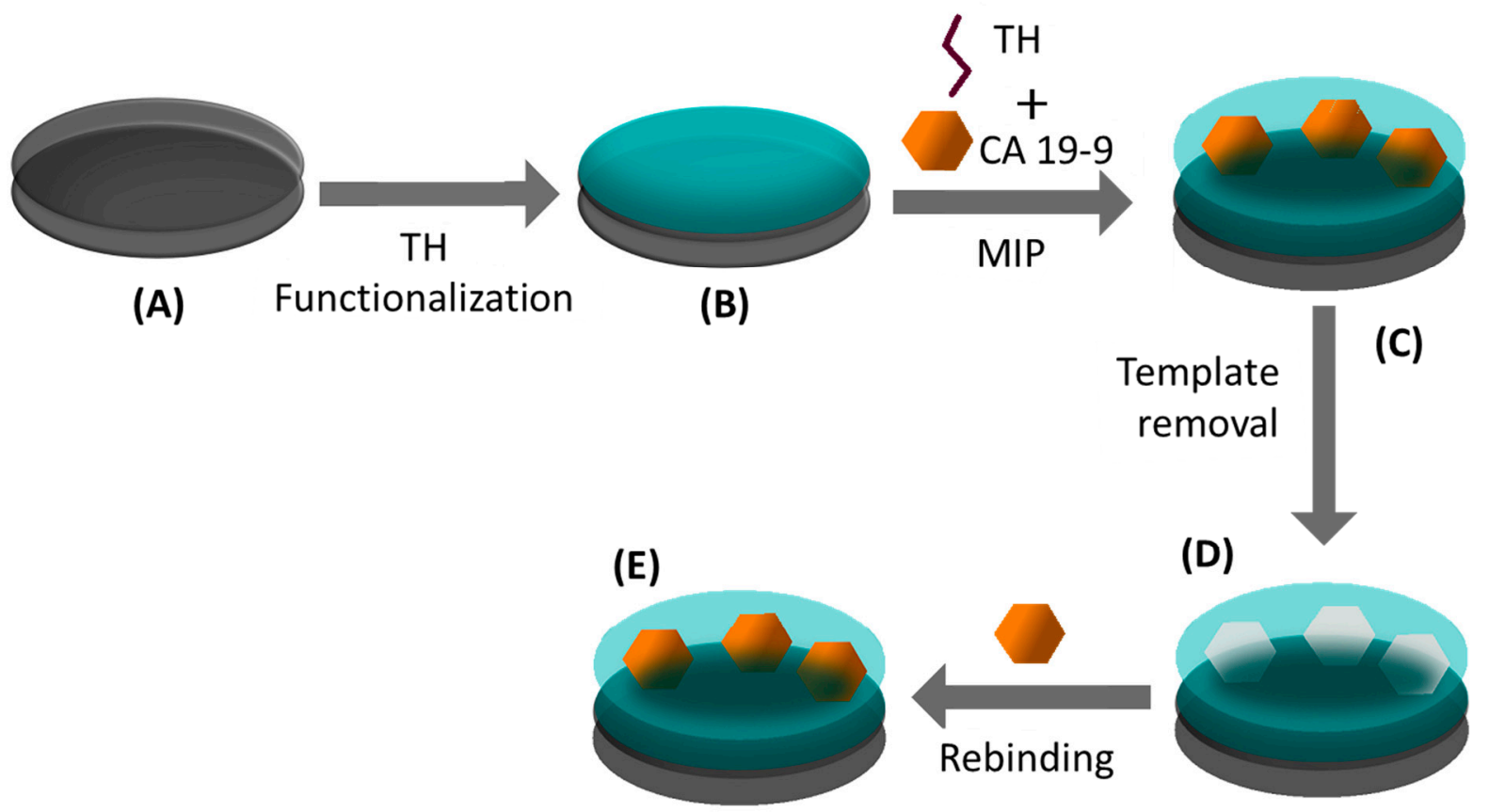

Figure 1. Schematic representation of the assembly of the biosensor. (A) Clean electrode; (B) modification of the electrode with thionine (TH); (C) electropolymerization of TH to generate the molecularly imprinted polymer (MIP) materials with the template CA 19-9; (D) template removal; and (E) CA 19-9 rebinding to the imprinted sites.

The resulting MIP/NIP electrodes were calibrated against CA 19-9 standard solutions, ranging from 0.010 to $100 \mathrm{U} / \mathrm{mL}$, prepared in $\mathrm{PhB}$ solution, $\mathrm{pH}$ 7.4. After a selected incubation time, the electrochemical reading of DPV was collected, using a pulse amplitude of $0.05 \mathrm{~V}$, a pulse width of $0.0167 \mathrm{~s}$, and pulse period of $0.1 \mathrm{~s}$.

\section{Results and Discussion}

\subsection{Formation and Electrochemical Studies of PTH on SPES}

The formation of the PTH film depends on the potential applied to the different substrates. In the first approaches reported, it was indicated that one should not go below a potential of $+1.1 \mathrm{~V}$ to undergo electropolymerization of $\mathrm{TH}$ [11]. Gao et al. considered that the upper potential limit in the potential sweep for the preparation of PTH was the determining factor in obtaining PTH. On the other hand, it has been proposed that the oxidation potential should not be less than $+0.9 \mathrm{~V}$, because the potential of the electrode should be greater than the potential in which the oxidation of TH is occurring [14]. After various discussions, it was also accepted that the formation of PTH depends on the pre-anodization of the surface [10], from which a positive charge can accumulate at the electrode surface to generate the $\mathrm{TH}$ cationic radical. Thus, initial explorations over the $\mathrm{TH}$ electropolymerization were conducted to understand which potential would be required to oxidize $\mathrm{TH}$ between -0.4 and $1.2 \mathrm{~V}$, at a scan rate of $0.050 \mathrm{~V} / \mathrm{s}$ for 15 cycles. The results obtained herein are shown in Figure 2. A shoulder peak at a maximum potential of $0.9 \mathrm{~V}$ was evident in both substrates (C-SPE and Au-SPE). In the presence of thionine, around $+0.9 \mathrm{~V}$, an irreversible oxidation of the monomer occurred, generating a radical cation, starting polymerization. 

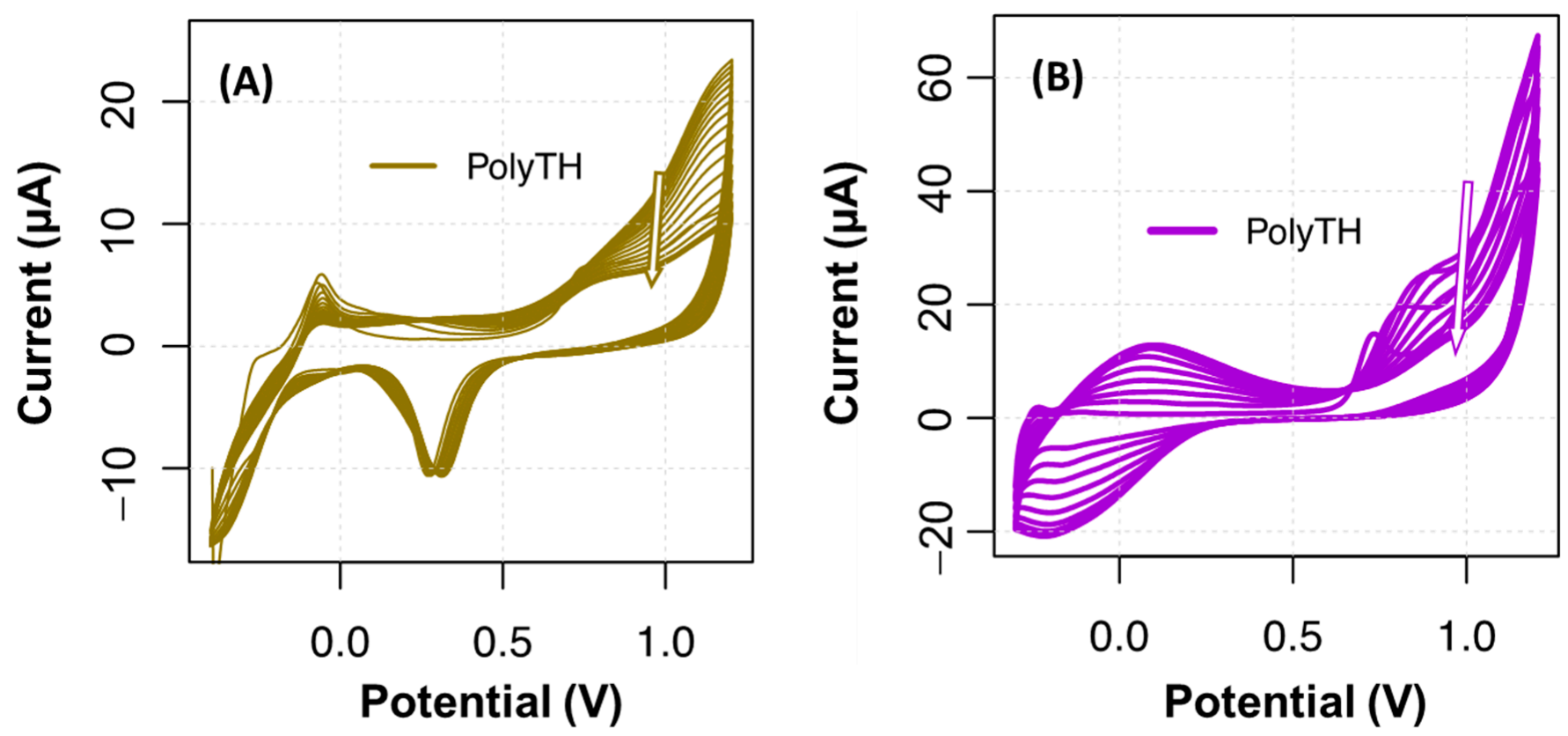

Figure 2. Consecutive voltammograms of a TH solution of $1.0 \times 10^{-3} \mathrm{M}$ prepared in phosphate buffer, between -0.4 and $1.2 \mathrm{~V}$, at a scan rate of $0.050 \mathrm{~V} / \mathrm{s}$ for 15 cycles: (A) PolyTH, onto gold surface (B) and carbon surface.

Globally, C-SPE had more intense current signals than Au-SPEs (Figure 2B), and the formation of a pair of (apparently) quasi-reversible peaks (at $+0.1 \mathrm{~V}$ and $-0.2 \mathrm{~V}$ ) was also evident. The formation of monomeric radicals occurred around $+0.9 \mathrm{~V}$ as mentioned above. The redox couples that were most noticeable at the carbon electrodes $(-0.2 \mathrm{~V} /+0.1 \mathrm{~V})$ were attributed to the oxidation/reduction of the polymer. Other redox pairs at more negative potentials are also described in the literature [17], $-0.23 \mathrm{~V} /-0.3 \mathrm{~V}$, which was attributed to the oxidation/reduction of monomers but on CNT-modified surfaces, so these pairs of redox were not evident in our case. It was assumed that this monomer pair (not found) decreased in each voltammetry cycle, while the polymer pairs $(-0.2 \mathrm{~V} /+0.1 \mathrm{~V})$ increased, indicating the growth of PTH. The progressive blockage of electrons in the PTH layer was seen by the current decrease in consecutive $\mathrm{CVs}$, with signals showing a tendency for an increased stabilization under an increasing number of CV cycles.

The electropolymerization curves on Au-SPE showed two oxidation peaks (Figure 2A), which were attributed to the redox reaction of the molecular layer being formed [18]. The anchor of TH to the Au-SPE has been proposed to occur covalently when TH is first modified into a diazonium salt, which undergoes electrical reduction through nitrogen cleavage under cathodic conditions, at about $0.9 \mathrm{~V}$ [19]. Eventually, the TH may bind to the gold via sulfur or nitrogen atoms, which are quite common bonds that are energetically favored.

It is known that by increasing the number of potential cycles during electropolymerization, the thickness of the polymeric film tends to be higher, but this is coupled to increased resistances that may hinder the electrochemical response. In the case of PTH, the increasing film thickness also causes a shift from electronic transfer in thin films to diffusion-controlled processes in thick films [13]. Yet, the purpose of having a first layer of TH/PTH was to have a stable binding between the electrode substrate (carbon or gold) and the subsequent MIP or NIP film. Thus, regardless of the number of cycles, the important aspect here was to have TH bound to the surface. From the studies made, it was clear that a stable PTH film was obtained for $15 \mathrm{CV}$ cycles. 


\subsection{Preparation of an Imprinted Film of PTH for CA 19-9}

The imprinted film was obtained by in situ electropolymerization of $\mathrm{TH}$ in the presence of CA 19-9 (MIP). First, both gold and carbon electrodes were modified with TH polymeric films formed under applied potentials or by simple casting, to ensure that the MIP film was strongly bound to the electrode surface. The use of PTH to generate a MIP material was also meant to have an electrochemical probe at the sensing material, which would avoid the need for an external redox probe. In this regard, Cheng et al. explored the properties of $\mathrm{TH}$ in a biosensor for DNA recognition by integrating zirconia-reduced graphene oxide nanocomposites [20]. Another use of TH as an electrochemical probe is the study reported by Zhou et al., in which graphene oxide was modified with TH [21].

The presence of CA 19-9 within the polymeric film being formed caused a displacement of the redox peaks toward more positive potentials in the cyclic voltammogram, both on carbon and gold substrates. This is shown in Figure 3, evidencing potential shifts of $50 \mathrm{mV}$ in the C-SPEs and $100 \mathrm{mV}$ in the Au-SPEs. It is important to note that the upper potential value of electropolymerization in the C-SPEs decreased from $+1.2 \mathrm{~V}$ to $+0.4 \mathrm{~V}$ (C-SPE). This was performed because Ahammad et al. 2011 reported that the formation of the polymer may be obtained under this narrower potential after subjecting the carbon surface to $+1.2 \mathrm{~V}$, which took place at the cleaning stage [1,14].
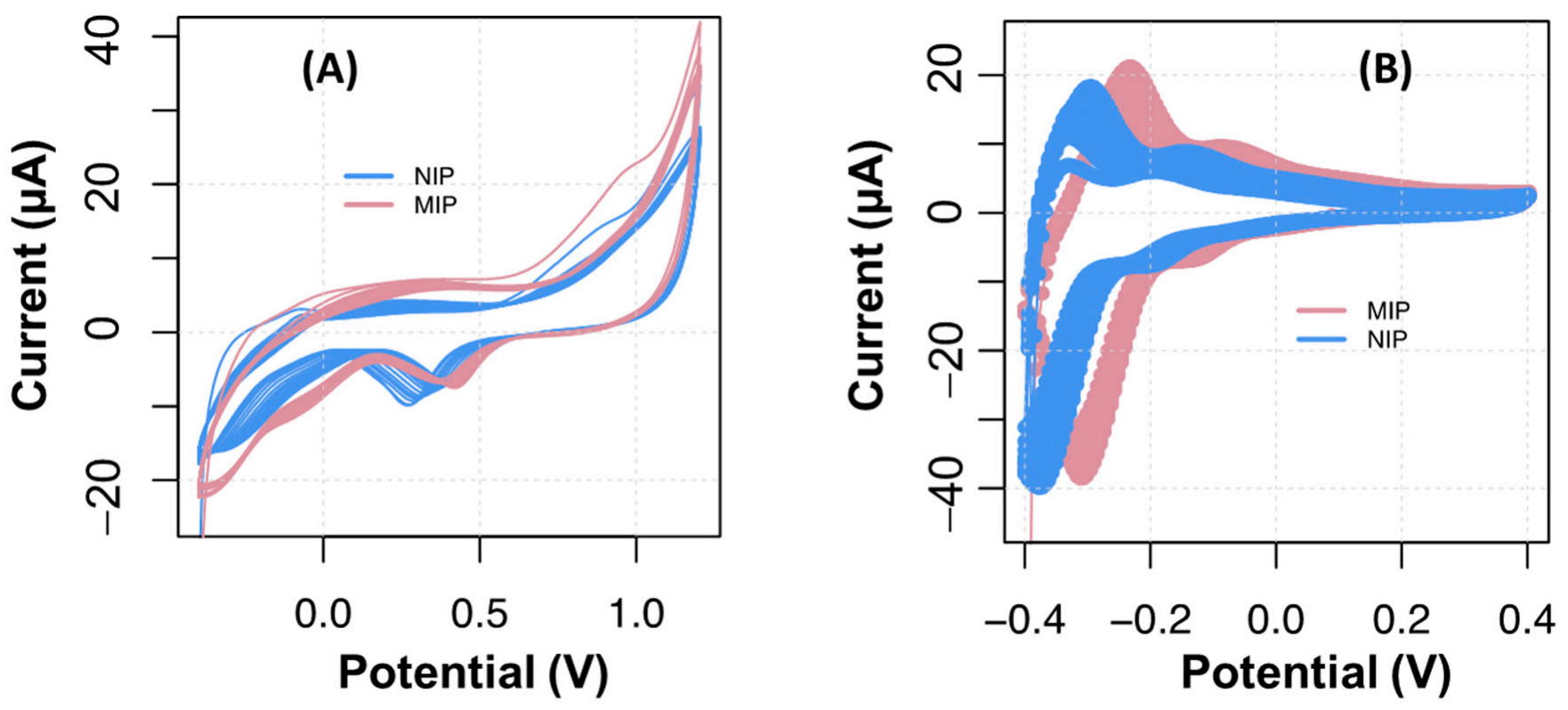

Figure 3. Consecutive voltammograms of a TH solution of $1.0 \times 10^{-3} \mathrm{M}$ prepared in phosphate buffer, pH 7.4, with CA 19-9 (MIP, pink), without CA 19-9 (NIP, blue), and first electropolymerization (gold line), on the (A) gold electrode and the (B) carbon electrode.

The fact that C-SPEs generated higher current values could turn out to be advantageous in terms of sensitivity of the analytical readings. C-SPEs are also less expensive than devices produced with gold-based inks.

\subsection{Raman Studies of TH on C-SPE}

Raman spectroscopy is one of the most powerful techniques for this purpose and has been widely used to study graphite and graphene. A characteristic Raman spectrum of the carbon electrodes is shown in Figure S1. The results showed that while the Raman peaks in crystalline graphene were the $\mathrm{G}\left(1579 \mathrm{~cm}^{-1}\right)$-associated symmetric E2g Raman mode [22], the intense peak at $1350 \mathrm{~cm}^{-1}$, called the D band, is related to the A1g breathing mode, and it was observed because graphite oxidation and the subsequent reduction of graphene oxide significantly alter the basal plane structure of graphene [23]. The shoulder in the spectrum was interpreted to be peak D" $\left(1512 \mathrm{~cm}^{-1}\right)$, which has been reported for some carbon-based 
materials. In addition, some weak peaks at $1165 \mathrm{~cm}^{-1}$ were observed in graphene oxide flakes and powders. Raman's modes for graphene were also observed with different kinds of defects, such as rings with different numbers of $C$ atoms and configurations of $\mathrm{C}-\mathrm{O}$ bonds. In these cases, a peak at $1615 \mathrm{~cm}^{-1}, \mathrm{D}^{\prime}$ band, has been attributed to the disorder-induced phonon mode due to crystal defects and defects in the graphene oxides [24].

By evaluating the Raman spectra of the same carbon electrode modified with $\mathrm{TH}$, one may determine if it is present and if $\mathrm{TH}$ interaction with carbon is covalent or noncovalent in nature. This was carried out by observing the $\mathrm{D}$ band $\left(1360 \mathrm{~cm}^{-1}\right)$ and following the alterations that may appear [25], as shown in Figure S2. The spectra of TH casted on carbon electrode is shown in Figure $4 \mathrm{~b}$. It showed the Raman bands at 1350 and $1579 \mathrm{~cm}^{-1}$, being a combination of both the characteristic bands of carbon and TH. The band at $1384 \mathrm{~cm}^{-1}$ corresponds to the $24 \mathrm{~cm}^{-1}$ Raman shift from the D band; this band is the defect band of carbon and it was visible in the Raman spectrum. As such, one could confirm the noncovalent interaction hypothesis, given that functionalization with TH does not introduce defects in the carbon network. In agreement with the construction of the biosensor, the first layer deposited was by absorption of $\mathrm{TH}$ on the surface, and apparently no covalent bonds were established.
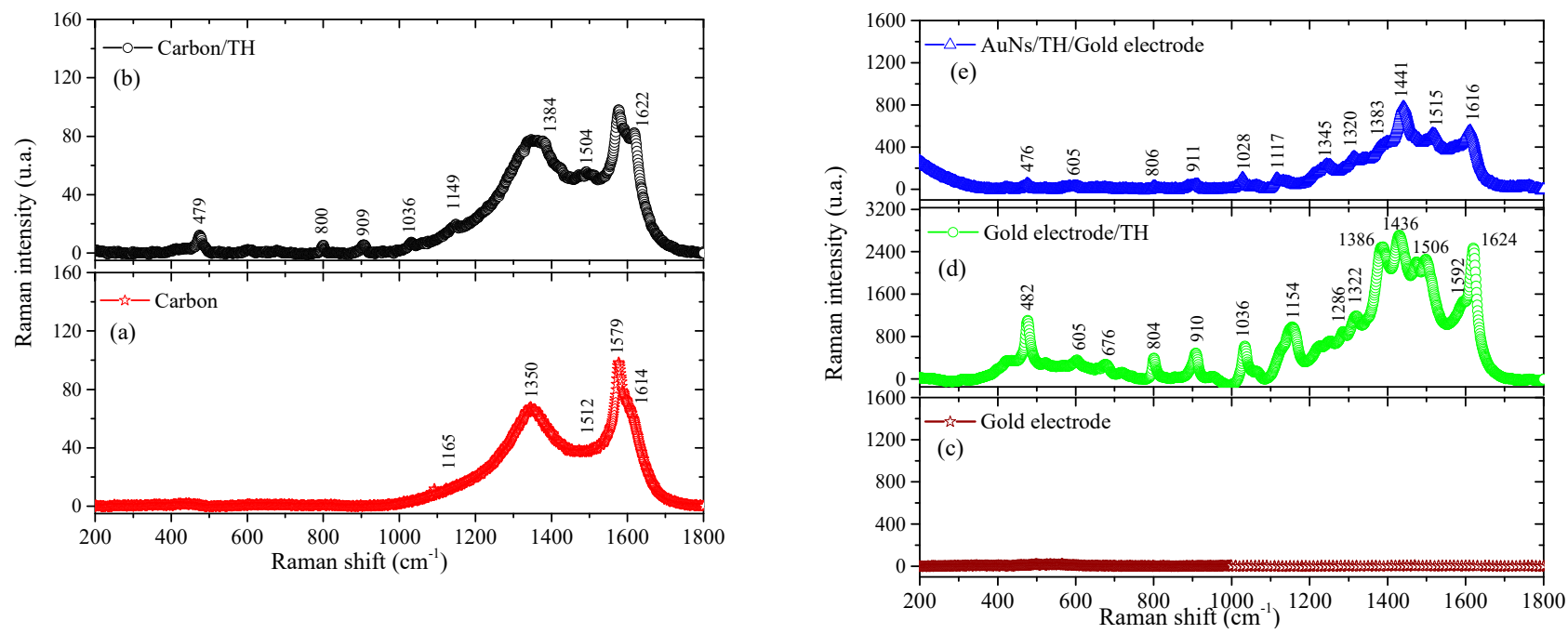

Figure 4. Raman spectra of carbon electrodes (a) or carbon electrodes modified with thionine (b), along with gold electrodes (c) or gold electrodes modified with TH (d), and SERS of AuNS with TH (e).

The eight main bands related to the presence of TH are shown in Table 1. Hutchinson et al., reported a band at $480 \mathrm{~cm}^{-1}$ that correlates well with the band at $479 \mathrm{~cm}^{-1}$ in the collected spectrum. This band was assigned to stretching of the C-S bond, central ring breathing, and Namino-H bond rocking [26]. Another band of TH was located $909 \mathrm{~cm}^{-1}$ and was assigned to ring breathing. The band at $1149 \mathrm{~cm}^{-1}$ was attributed to ring vibrations together with stretching vibrations of the $\mathrm{N}-\mathrm{H}$ bond in the amino group. Finally, the important bands at 1504 and $1622 \mathrm{~cm}^{-1}$ were assigned to the aromatic ring stretching and Namino-H bending $[19,27]$. 
Table 1. Raman bands of a TH solution on carbon or gold substrate assigning its presence and TH solid.

\begin{tabular}{|c|c|c|c|c|}
\hline $\begin{array}{l}\text { Thionine Solid } \\
\left(\lambda_{\text {exe }}=645 \mathrm{~nm}\right)\end{array}$ & $\begin{array}{l}\text { Thionine/ } \\
\text { Carbon }\end{array}$ & $\begin{array}{l}\text { Thionine/ } \\
\text { Gold }\end{array}$ & $\begin{array}{l}\text { AuNS/Thionine/ } \\
\text { Gold }\end{array}$ & Assignments \\
\hline 1618 & 1622 & 1624 & 1616 & $v(\mathrm{C}-\mathrm{C})_{\text {ring }}+v_{\mathrm{as}}(\mathrm{C}-\mathrm{N}-\mathrm{C})_{\text {ring }}+\delta\left(\mathrm{N}_{\mathrm{amino}}-\mathrm{H}\right)$ \\
\hline 1503 & 1504 & 1506 & 1515 & $v(\mathrm{C}-\mathrm{C})_{\text {ring }}+\delta\left(\mathrm{N}_{\mathrm{amino}}-\mathrm{H}\right)$ \\
\hline \multirow[t]{2}{*}{1475} & & 1475 & 1476 & $v(\mathrm{C}-\mathrm{C})_{\text {ring }}$ \\
\hline & & 1436 & 1441 & $v(\mathrm{C}-\mathrm{C})_{\text {ring }}+v_{\mathrm{as}}(\mathrm{C}-\mathrm{N}=\mathrm{C})_{\text {ring }}+\operatorname{rock}\left(\mathrm{N}_{\text {bridge }}-\mathrm{H}\right)$ \\
\hline 1387 & 1384 & 1386 & 1386 & H-bending + ring-stretching \\
\hline 1320 & & 1322 & 1320 & $\operatorname{rock}(\mathrm{C}-\mathrm{H})+\delta\left(\mathrm{N}_{\mathrm{amino}}-\mathrm{H}\right)$ \\
\hline 1283 & & 1286 & & $v(\mathrm{C}-\mathrm{C})_{\text {ring }}+v\left(\mathrm{~N}_{\text {ring }}-\mathrm{H}\right)$ \\
\hline 1224 & & 1228 & 1214 & $\beta(\mathrm{C}-\mathrm{H})+$ wag $(\mathrm{C}-\mathrm{H})$ \\
\hline \multirow[t]{3}{*}{1150} & 1149 & 1154 & & $v(C-C)_{\text {ring }}$ \\
\hline & & 1132 & 1137 & $v(C-C)$ di(thionine $)$ \\
\hline & & 1059 & 1114 & $v\left(\mathrm{~N}_{\text {amino }}-\mathrm{H}\right)$ \\
\hline 1033 & 1036 & & 1028 & $\beta(C-H)+v_{a s}(C-S)+\operatorname{rock}(C-H)$ \\
\hline 887 & 909 & 910 & 889 & ring breathing \\
\hline 804 & 800 & 804 & 802 & \\
\hline 685 & & 676 & & ring breathing $+v(C-S)+v(C-H)$ \\
\hline 605 & & 605 & 605 & $\beta(\mathrm{C}-\mathrm{C})+\operatorname{rock}\left(\mathrm{N}_{\mathrm{amino}}-\mathrm{H}\right)+\operatorname{rock}(\mathrm{C}-\mathrm{H})$ \\
\hline 479 & 479 & 482 & 480 & $\begin{array}{l}v(\mathrm{C}-\mathrm{S})+\text { central ring breathing + rock } \\
\qquad\left(\mathrm{N}_{\mathrm{amino}}-\mathrm{H}\right)\end{array}$ \\
\hline
\end{tabular}

Moreover, there was an insignificant difference between the ratio $\mathrm{I}_{\mathrm{D}} / \mathrm{I}_{\mathrm{G}}$ for 0.94 (carbon) and 1.04 (TH-carbon) presented in Table S1. As such, one could confirm the noncovalent interaction hypothesis, given that functionalization with $\mathrm{TH}$ does not introduce defects in the carbon network.

\subsection{Raman Studies of TH on Au-SPE}

The Raman spectra collected for the gold electrode substrate (Figure 4c) had no relevant peaks to comment, as expected for a gold material observed in Raman spectroscopy. In contrast, the modification of this gold electrode with $\mathrm{TH}$ solution that underwent the $\mathrm{CV}$ procedure yielded a spectrum with a wide range of vibrations, as evidenced in Figure $4 \mathrm{~d}$.

The presence of TH on the gold electrode was evidenced by four main bands at 482 1059,1386 , and $1624 \mathrm{~cm}^{-1}$ and twelve weaker bands at $605,676,804,910,1132,1154,1228$, $1286,1322,1436,1476$, and $1506 \mathrm{~cm}^{-1}$; the location of the bands as well as their respective assignments are represented in Table 1 . The first four bands can be grouped by their vibration caused by stretching of the C-S bond, central ring breathing, and Namino-H bond rocking. The second one includes the contribution of stretching of C-N-C together with $\mathrm{C}-\mathrm{NH}$ vibrations, whereas the last arises from aromatic ring stretching and Namino-H bending $[19,26,27]$. The band at $1506 \mathrm{~cm}^{-1}$ corresponded to central ring breathing, and Namino-H bond rocking of the amino group and the band at $1436 \mathrm{~cm}^{-1}$ were assigned to the formation of amino bridges between two phenothiazine molecules [19]. The bands of leucothionine were at 1154,1228, and $1386 \mathrm{~cm}^{-1}$. The signal corresponding to the vibrations of the ring of the dimeric structure formed was evidenced with the band at $1132 \mathrm{~cm}^{-1}$. The band located near $605 \mathrm{~cm}^{-1}$ corresponded to the oscillation of the amino group [19]. The band at $1436 \mathrm{~cm}^{-1}$ arising from the asymmetric stretching vibrations of the $\mathrm{C}=\mathrm{N}$ bond in the central ring, together with that at $1475 \mathrm{~cm}^{-1}$, connected with the vibrations of quinoid rings, which suggest the transformation of grafted TH into the oxidized form [19].

Overall, the presence of TH on the gold substrate (as well as on the carbon) was clearly validated by the Raman studies.

\subsection{Response of the MIP Film to CA 19-9 in C-SPE}

For most dyes, including $\mathrm{TH}$, the simplest immobilization technique consists of their adsorption to suitable substrates, such as carbon. In addition, monolayers of these 
molecules have been shown to be stably adsorbed on gold surfaces [28]. Thus, TH was first adsorbed into the carbon electrodes, by casting the $\mathrm{TH}$ solution along $1 \mathrm{~h}$. This adsorption would allow a strong binding between the carbon substrate and the MIP layer formed after, thereby contributing to increase the stability of the electrochemical response. Considering that $\mathrm{TH}$ was not chemically modified, it is possible that the molecule established $\pi-\pi$ stack interactions with the aromatic rings on the carbon substrate and electrostatic interactions between the -S- and the three amine groups on $\mathrm{TH}$ and the oxidized functional groups on the carbon substrate (which were likely to be present after acidic cleaning).

The DPV technique was used to follow the TH peak on the substrate, confirmed by the appearance of a peak at around $-0.35 \mathrm{~V}$ (Figure 5). The formation of the MIP film was suggested by the increasing reduction current produced by the electrodes and a potential shift. In contrast, the NIP yielded a more intense potential shift for a lower peak current.
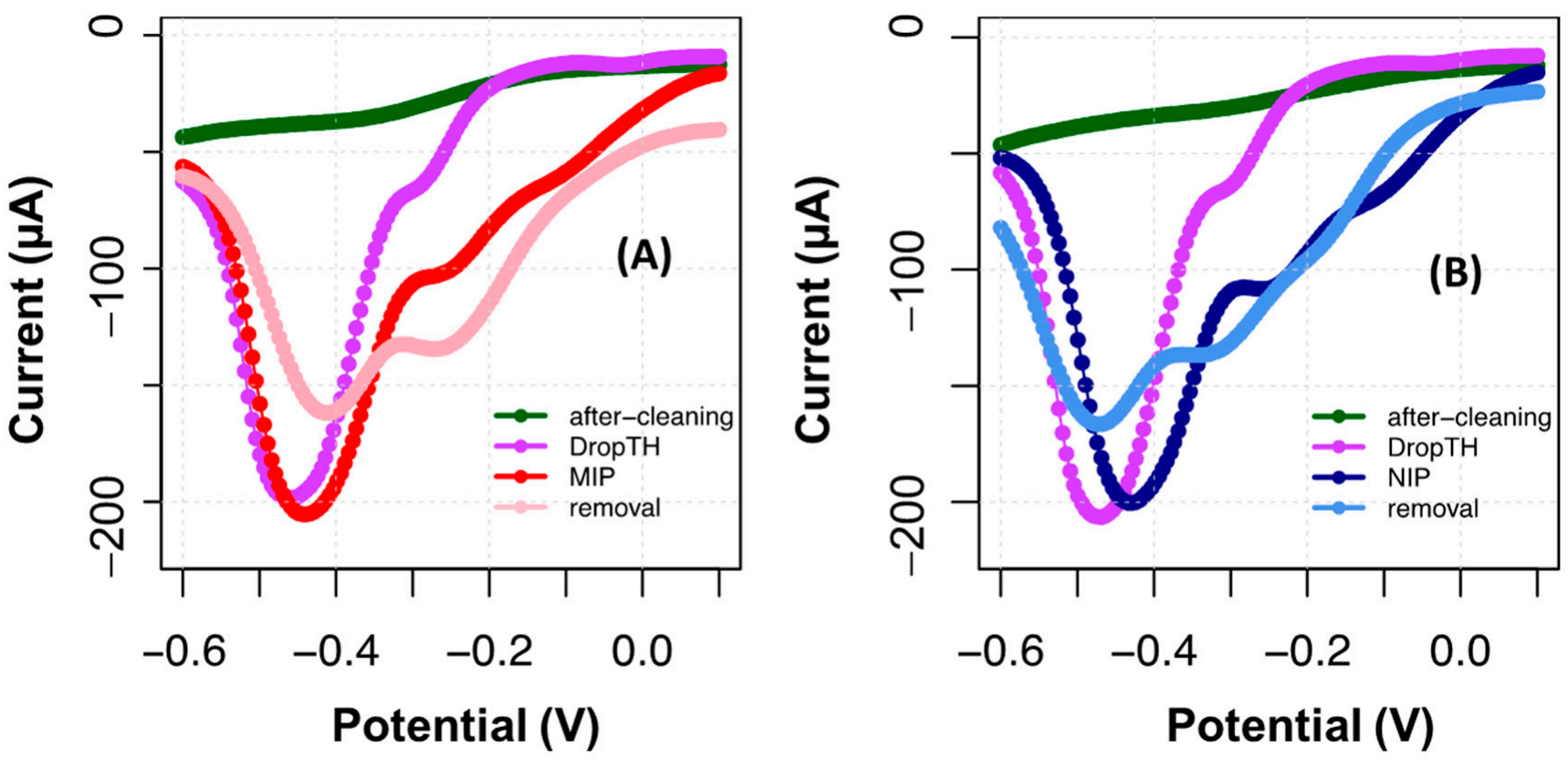

Figure 5. DPV voltammogram of C-SPE after cleaning of surface (green), drop-casting TH (violet), electropolymerizing TH with or without CA 19-9 (red, MIP, and blue, NIP), and removing the template (coral, MIP, and light-blue, NIP). (A) represents the MIP assembly and (B) the NIP assembly.

After template removal, a significant current decrease was observed, along with a shift in peak potentials. This tendency was more evident in the NIP, which was also subject to a template removal procedure, only for control purposes. This behavior of the NIP evidenced the extraction from the electrode surface of di- to oligomeric compounds to $\mathrm{TH}$ that were not firmly attached. It could also signal chemical changes occurring on PTH after contact with oxalic acid. In addition, the peak shifting to $-0.25 \mathrm{~V}$ in the NIP also became more intense than that in MIP. By comparing this behavior with the control NIP, the changes in the MIP could be related to the fact that some protein molecules remained entrapped within the polymeric network.

The ability of the MIP film to bind CA 19-9 was tested by performing calibration curves with standard solutions of the protein. This was performed only after stabilization of the $\mathrm{MIP} / \mathrm{TH}$ surface, by successive incubations in PhB, for $20 \mathrm{~min}$, until a stable reading was reached. The calibration was made from the lowest to the highest concentration, incubating consecutively each standard solution in the same electrode. The standard solutions of CA 19-9 prepared for this purpose had $0.010,0.030,0.10,0.30,1.0,3.0,10,31$, and $100 \mathrm{U} / \mathrm{mL}$.

The results obtained are shown in Figure 6. In general, from the two peaks observed in the voltammograms of the MIP, the peak current at about $-0.4 \mathrm{~V}$ decreased its intensity with increasing concentrations of CA 19-9, while the peak at $-0.25 \mathrm{~V}$ displayed a random 
behavior. In contrast, the voltammograms of the NIP displayed a more intense peak at about $-0.25 \mathrm{~V}$, which also displayed a random behavior, and a negligible peak current at about $-0.4 \mathrm{~V}$. This global random behavior of the NIP suggested the absence of specific binding sites on the polymeric network to capture CA 19-9.
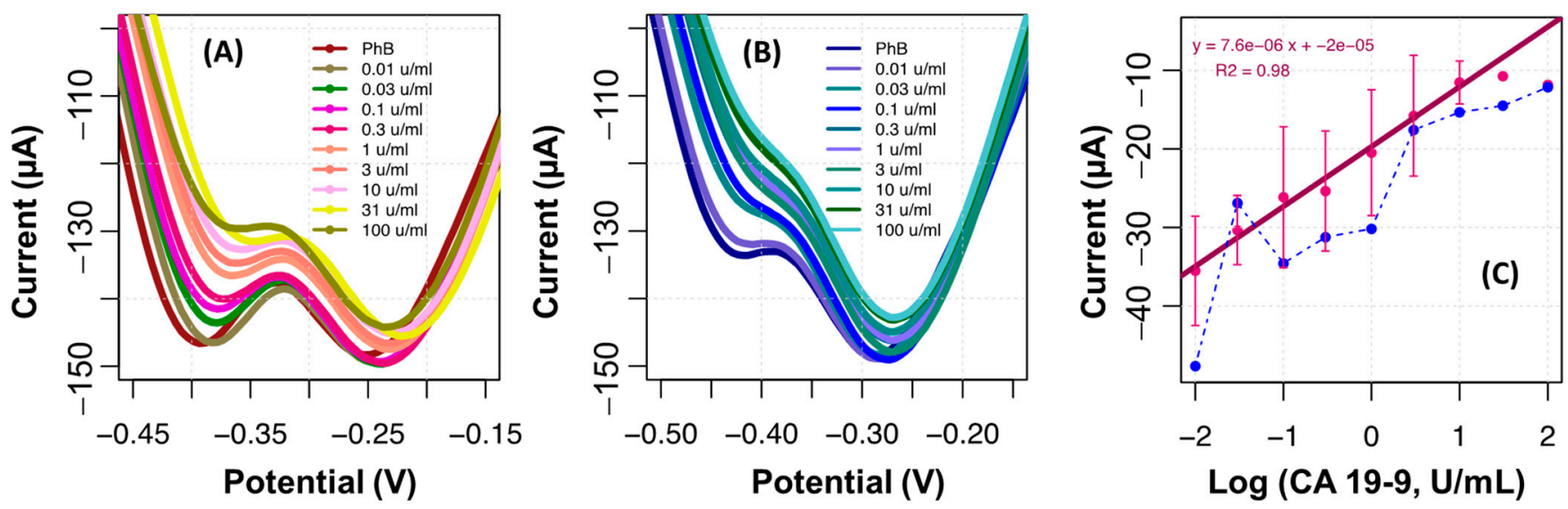

Figure 6. DPV voltammograms of MIP (A) and NIP (B) films assembled on C-SPE and incubated consecutively with increasing concentrations of CA 19-9 standard solutions, from 0.10 to $100 \mathrm{U} / \mathrm{mL}$, along with the corresponding average calibration plots (C) plotting MIP as dark-pink, and NIP as light-blue.

Overall, a greater difference between MIP and NIP films was observed at the peak located at about $-0.4 \mathrm{~V}$. This peak also displayed more intense peak current changes for consecutive concentration variations, thereby generating calibrations of greater sensitivity. Having calibrations plotted under this condition, the analytical performance of the biosensor in C-SPEs showed a linear trend in the concentration range studied, up to $10 \mathrm{U} / \mathrm{mL}$ (Figure 6c). The average linear regression was $I(\mathrm{~A})=7.6 \times 10^{-6} \times \log (\mathrm{CA} 19-9, \mathrm{U} / \mathrm{mL})$ $+2 \times 10^{-5}$, with an $\mathrm{R}$ squared $>0.98$, down to $0.010 \mathrm{U} / \mathrm{mL}$. The calibrations in the NIP displayed a random response, as mentioned, thereby confirming that the response of the MIP was selective for CA 19-9.

\subsection{Response of the MIP Film to CA 19-9 in Au-SPE}

The first layer with $\mathrm{TH}$ was made by casting the solution and allowing adsorption and by electropolymerization of TH on top of the electrodes. From the two approaches, electropolymerization yielded the most stable response and was therefore selected [29]. After electropolymerization of $\mathrm{TH}$, the gold electrode displayed an increase in the current value, along with the appearance of a potential peak around $-0.45 \mathrm{~V}$ (Figure $7 \mathrm{~A}$ ). This suggests the formation of the polymeric film of $\mathrm{TH}$, which seemed to be corroborated by the intense purple coloration obtained in the working electrode (Figure 7A, pictured in inset that is stable within time and after washing).

The formation of the MIP was confirmed by a marked increase in the reducing current in the potential peak that appeared at $-0.5 \mathrm{~V}$. As can be seen in Figure 7 , the increase in the conductivity of the electrode in the MIP was much greater with respect to the NIP. Another difference marked by the presence of CA 19-9 was the small shift in the peak to more negative potentials in the MIP, while in the NIP, it shifted to more positive potentials. 

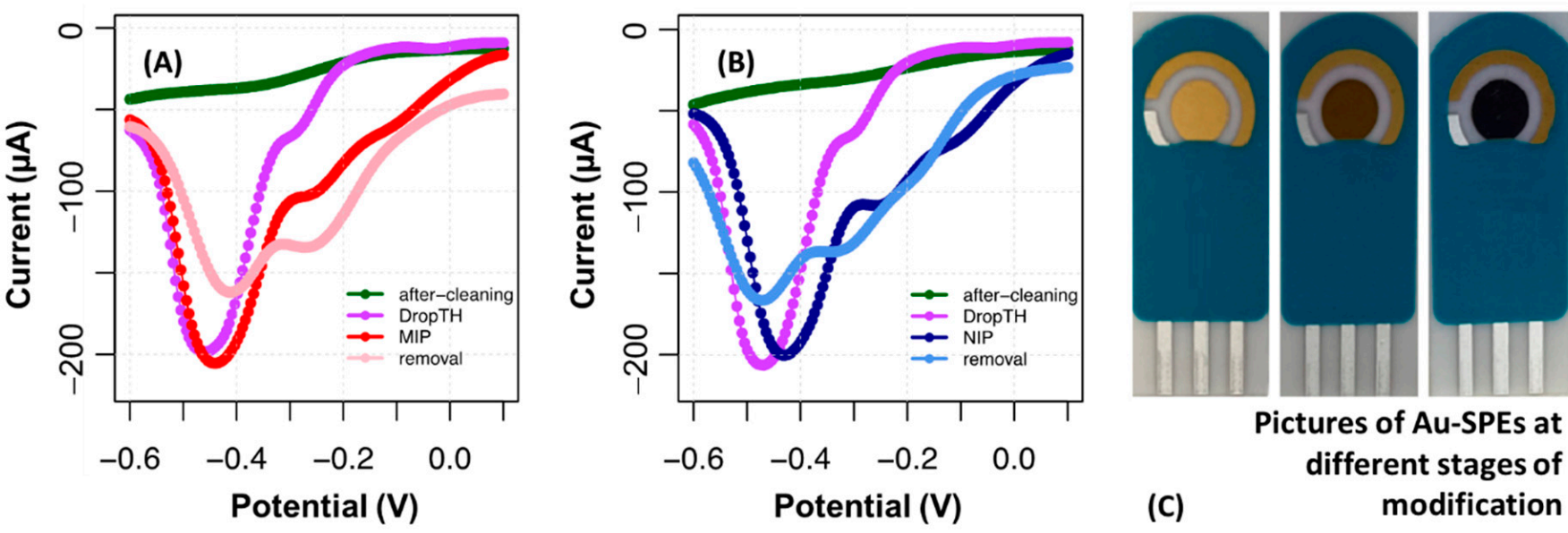

Figure 7. DPV voltammogram of Au-SPE after cleaning of surface (green), PTH (violet), electropolymerizing TH with or without CA 19-9 (red, MIP, and blue, NIP), and removing the template (coral, MIP, and light-blue, NIP). MIP represented in (A) and NIP in (B). SPE with the color changes in the working electrode in the different construction phases $(\mathbf{C})$.

The removal of CA 19-9 is a fundamental step to obtain the imprinted cavities that are directly related to the sensitivity of the biosensor. The removal of the protein was conducted by incubating oxalic acid on the working electrode for $1 \mathrm{~h}$. The correct formation of cavities in the sensor was verified by decreasing the reduction peak and shifting to higher potentials. The NIP also yielded decreasing currents; however, the peak obtained had little resolution compared to the background signal.

The response of the MIP film on Au-SPE to CA 19-9 was tested by calibration curves, which were made similarly to the studies made with C-SPEs. The typical results so obtained are shown in Figure 8. Overall, the reduction peak signaling the presence of $\mathrm{PTH}$ was also the presence at about $-0.5 \mathrm{~V}$ (it is important to note that the solutions were deaerated with nitrogen before reading) and the reduction peak tended to decrease in the presence of CA 19-9. This tendency showed a linear dependency with log CA 19-9 concentration from $0.10 \mathrm{U} / \mathrm{mL}$ to $100 \mathrm{U} / \mathrm{mL}$. As before, the NIP displayed a random behavior, thereby confirming that the response obtained for CA 19-9 depended mostly on interactions between the target protein and the binding sites.
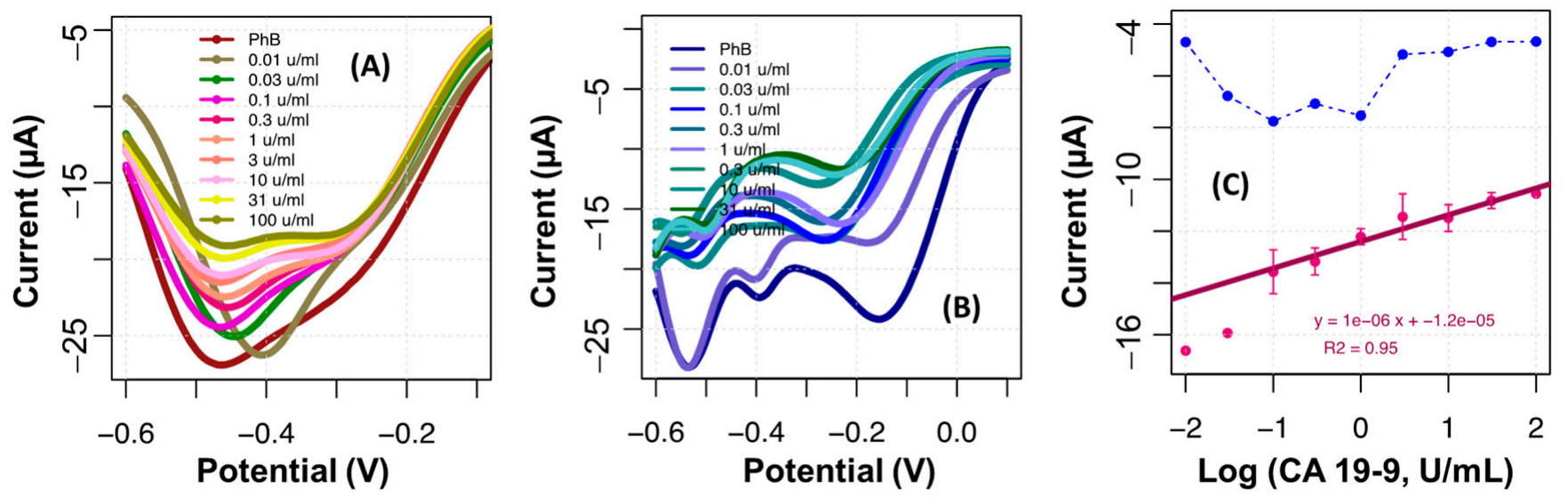

Figure 8. DPV voltammograms of MIP (A) and NIP (B) films assembled on Au-SPE and incubated consecutively with increasing concentrations of CA 19-9 standard solutions, from 0.10 to $100 \mathrm{U} / \mathrm{mL}$, along with the corresponding average calibration plots $(\mathbf{C})$, plotting MIP as dark-pink, and NIP as light-blue. 


\subsection{SERS on TH Readings}

Attempts to increase the signal by SERS studies were made by casting on the gold substrate TH linked to AuNS. The TEM shown in Figure S3 confirmed the formation of AuNS. The typical Raman band of TH was observed in the spectra obtained and shown in Table 1. The intensity of the spectrum obtained by SERS was two times lower than that obtained with TH casted directly on the gold electrode (Figure 4e).

The Raman spectra shown in Figure S4A corresponds to the absorption of TH in glass and in the carbon substrate. In the other graph, Figure S4B, the absorption of TH followed by electropolymerization is shown in carbon electrodes, TH/PTH. It is interesting to note that the spectra were apparently quite similar, showing the strong Raman bands of the TH. The most predominant bands observed were found at 486, 811, 914, 1036, 1389, 1504, and $1625 \mathrm{~cm}^{-1}$, and their vibrational characteristics are listed in Table 1.

In the SERS spectrum, it was expected that the Raman bands would be more visible (Figure S5B), that is, an increase in intensity would be observed throughout the spectrum. This may be due to the fact that the distribution of the AuNS was not homogeneous throughout the surface of the electrode. As the AuNS/TH layer was not homogeneously distributed on the surface, it was difficult to observe the SERS effect (Figure S5A), unlike the spectrum observed on the surface of the gold electrodes (Figure S5B), where the intensity of the spectrum of the TH bands appeared with greater intensity compared to SERS. Hence, we can conclude that the distribution of the AuNS/TH did not occur homogeneously throughout the surface. However, on the surface of the gold electrodes, we had a homogeneous layer of PTH that covered the entire surface of the gold. Any reading point of the Raman laser will find PTH deposited and its effect intensified by the surface of the gold in which it was absorbed.

The band located at $1616 \mathrm{~cm}^{-1}$ corresponded to a shift of $8 \mathrm{~cm}^{-1}$ of the band corresponding to aromatic ring stretching and Namino-H bending for TH on Au-SPE $\left(1624 \mathrm{~cm}^{-1}\right)$. The band located at $1515 \mathrm{~cm}^{-1}$ could be attributed to central ring breathing, and Namino- $\mathrm{H}$ bond rocking of the amino group such as TH on the Au-SPE band was located at $1506 \mathrm{~cm}^{-1}$. The band at $1441 \mathrm{~cm}^{-1}$ attributed to the asymmetric stretching vibrations of $\mathrm{C}=\mathrm{N}$ bond in the central ring decreased by $5 \mathrm{~cm}^{-1}$ in TH on Au-SPE $\left(1436 \mathrm{~cm}^{-1}\right)$. The greatest decrease corresponded to the attributed band vibrations of the ring of the dimeric at $1214 \mathrm{~cm}^{-1}$, being $14 \mathrm{~cm}^{-1}$ for TH on Au-SPE $\left(1228 \mathrm{~cm}^{-1}\right)$. Despite the peaks appearing with less intensity in both spectra, this displacement of the band can be associated with loss or gains of energy between the atomic vibrations.

Overall, the signal obtained by direct reading to $\mathrm{TH}$ on the gold electrode was greater than that observed with the TH on the AuNS. In fact, there was no reasonable explanation for this observation, considering that the gold AuNS had a much greater surface area than the eventually flat gold surface on the Au-SPE (which has great roughness because it was produced by printing a gold electrode on a ceramic substrate). Likely, this comparison was not valid and should require additional studies with increasing concentrations of the AuNS/TH, but this was also made to work very expensively, which is not desired for a POC system.

Overall, the results obtained demonstrate that the Au-SPE/TH substrate had potential to undergo a SERS reading to CA 19-9 binding in consecutive incubations of standard solutions, which would lead to a complementary and dual response on the same sensing unit. After incubation of the standard solutions, the electrochemical reading (which is nondestructive) could be followed by a SERS reading for providing additional information, in a similar approach to that described in Castaño-Guerrero et al., 2021 [16] (without AuNS and having the signal enhancement at the substrate). This would help increase the accuracy of the analytical response. 


\section{Conclusions}

A new MIP material for CA 19-9 was presented for electrochemical reading of this cancer biomarker. When compared to a control, the MIP showed selective and sensitive responses in reduction peak currents of the sensing film that were concentration-dependent. The materials obtained were monitored by DPV and analyzed by Raman spectroscopy, aiming to confirm the presence of $\mathrm{TH}$ and possible derived species. Raman spectroscopy was useful to determine the presence of $\mathrm{TH}$ and its different interactions with respect to each substrate studied. The results obtained from the characterization of the TH bands suggest wide range of potential applications.

Importantly, TH was efficient as an indicator of the electrochemical signal, revealing the SPEs to be self-indicated and label-free to detect CA 19-9. DPV was a useful technique to monitor the effect of CA 19-9 on the electrode, being an overly sensitive technique. Moreover, studies made with SERS suggested that the gold substrate with TH could further lead to complementary data, in a dual-detection scheme on the same electrode.

Supplementary Materials: The following supporting information can be downloaded at: https: //www.mdpi.com/article/10.3390/chemosensors10030092/s1, Figure S1: Raman spectra of the carbon electrode at room temperature, signaling peaks G, D, D', D" and D*; Figure S2: SERS spectra of TH powder showing the most relevant peaks; Figure S3: TEM images of AuNS; Figure S4: Raman spectra of TH, (A) (blue) on carbon electrodes and (green) on glass, both substrates drops with $\mathrm{TH}$, (B) (pink) spectra of PTH on carbon substrate. Figure S5: SERS spectra of (A) TH/AuNS, (blue) on glass and (green) on gold, (B) (pink) spectra of PTH on gold Substrate; Table S1: Information about ratio between intensities and amplitude of carbon bands, D, D", and G.

Author Contributions: Conceptualization, Y.C.-G. and F.T.C.M.; data curation, Y.C.-G. and Y.R.-B.; formal analysis, Y.C.-G., Y.R.-B., F.T.C.M. and W.R.B.; funding acquisition, W.R.B., E.F. and M.G.F.S.; investigation, Y.C.-G., Y.R.-B. and F.T.C.M.; methodology, Y.C.-G., Y.R.-B. and F.T.C.M.; project administration, W.R.B. and M.G.F.S.; resources, E.F. and M.G.F.S.; supervision, F.T.C.M. and M.G.F.S.; validation, Y.C.-G. and Y.R.-B.; visualization, Y.C.-G., W.R.B. and E.F.; writing-original draft, Y.C.-G. and Y.R.-B.; writing-review and editing, F.T.C.M., W.R.B., E.F. and M.G.F.S. All authors have read and agreed to the published version of the manuscript.

Funding: This research was funded by Fundação para a Ciência e Tecnologia grant number SFRH/BD /145590/2019.

Institutional Review Board Statement: Not applicable.

Informed Consent Statement: Not applicable.

Acknowledgments: Y.C.-G. acknowledges the PhD grant reference SFRH/BD/145590/2019 to Fundação para a Ciência e Tecnologia.

Conflicts of Interest: The authors declare no conflict of interest.

\section{References}

1. Ahammad, A.J.S.; Rahman, M.M.; Xu, G.-R.; Kim, S.; Lee, J.-J. Highly sensitive and simultaneous determination of hydroquinone and catechol at poly(thionine) modified glassy carbon electrode. Electrochim. Acta 2011, 56, 5266-5271. [CrossRef]

2. Baig, N.; Saleh, T.A. Electrodes modified with 3D graphene composites: A review on methods for preparation, properties and sensing applications. Microchim. Acta 2018, 185, 283. [CrossRef]

3. Demir, E.; Silah, H.; Uslu, B. Phthalocyanine Modified Electrodes in Electrochemical Analysis. Crit. Rev. Anal. Chemistr. 2020, 1-37. [CrossRef] [PubMed]

4. $\quad$ Katic, V.; dos Santos, P.L.; dos Santos, M.F.; Pires, B.M.; Loureiro, H.C.; Lima, A.P.; Queiroz, J.C.M.; Landers, R.; Muñoz, R.A.A.; Bonacin, J.A. 3D Printed Graphene Electrodes Modified with Prussian Blue: Emerging Electrochemical Sensing Platform for Peroxide Detection. ACS Appl. Mater. Interfaces 2019, 11, 35068-35078. [CrossRef]

5. Chipeture, A.T.; Apath, D.; Moyo, M.; Shumba, M. Multiwalled carbon nanotubes decorated with bismuth (III) oxide for electrochemical detection of an antipyretic and analgesic drug paracetamol in biological samples. J. Anal. Sci. Technol. 2019, 10, 22. [CrossRef]

6. Özcan, A.; İlkbaş, S.; Atılır Özcan, A. Development of a disposable and low-cost electrochemical sensor for dopamine detection based on poly(pyrrole-3-carboxylic acid)-modified electrochemically over-oxidized pencil graphite electrode. Talanta 2017, 165, 489-495. [CrossRef] 
7. Santos, D.P.; Zanoni, M.V.B.; Bergamini, M.F.; Chiorcea-Paquim, A.-M.; Diculescu, V.C.; Oliveira Brett, A.-M. Poly(glutamic acid) nanofibre modified glassy carbon electrode: Characterization by atomic force microscopy, voltammetry and electrochemical impedance. Electrochim. Acta 2008, 53, 3991-4000. [CrossRef]

8. Pérez-Ràfols, C.; Serrano, N.; Manuel Díaz-Cruz, J.; Ariño, C.; Esteban, M. Penicillamine-modified sensor for the voltammetric determination of $\mathrm{Cd}(\mathrm{II})$ and $\mathrm{Pb}(\mathrm{II})$ ions in natural samples. Talanta 2015, 144, 569-573. [CrossRef]

9. Benvidi, A.; Banaei, M.; Tezerjani, M.D.; Molahosseini, H.; Jahanbani, S. Impedimetric PSA aptasensor based on the use of a glassy carbon electrode modified with titanium oxide nanoparticles and silk fibroin nanofibers. Mikrochim. Acta 2017, 185, 50. [CrossRef]

10. Dempsey, E.; Diamond, D.; Collier, A. Development of a biosensor for endocrine disrupting compounds based on tyrosinase entrapped within a poly(thionine) film. Biosens. Bioelectron. 2004, 20, 367-377. [CrossRef]

11. Yang, R.; Ruan, C.; Dai, W.; Deng, J.; Kong, J. Electropolymerization of thionine in neutral aqueous media and $\mathrm{H}_{2} \mathrm{O}_{2}$ biosensor based on poly(thionine). Electrochim. Acta 1999, 44, 1585-1596. [CrossRef]

12. Topçu, E.; Alanyalığlu, M. Electrochemical formation of poly(thionine) thin films: The effect of amine group on the polymeric film formation of phenothiazine dyes. J. Appl. Polym. Sci. 2014, 131, 39686. [CrossRef]

13. Ferreira, V.; Tenreiro, A.; Abrantes, L.M. Electrochemical, microgravimetric and AFM studies of polythionine films: Application as new support for the immobilisation of nucleotides. Sens. Actuators B Chem. 2006, 119, 632-641. [CrossRef]

14. Gao, Q.; Cui, X.; Yang, F.; Ma, Y.; Yang, X. Preparation of poly(thionine) modified screen-printed carbon electrode and its application to determine NADH in flow injection analysis system. Biosens. Bioelectron. 2003, 19, 277-282. [CrossRef]

15. Romaguera-Barcelay, Y.; Moreira, J.A.; González-Aguilar, G.; Almeida, A.; Araujo, J.P.; Pérez de la Cruz, J. Synthesis of orthorhombic rare-earth manganite thin films by a novel chemical solution route. J. Electroceram. 2011, 26, 44-55. [CrossRef]

16. Castaño-Guerrero, Y.; Moreira, F.T.C.; Sousa-Castillo, A.; Correa-Duarte, M.A.; Sales, M.G.F. SERS and electrochemical impedance spectroscopy immunoassay for carcinoembryonic antigen. Electrochim. Acta 2021, 366, 137377. [CrossRef]

17. Ghica, M.E.; Brett, C.M.A. Poly(brilliant green) and poly(thionine) modified carbon nanotube coated carbon film electrodes for glucose and uric acid biosensors. Talanta 2014, 130, 198-206. [CrossRef] [PubMed]

18. Li, R.; Cao, L.; Liang, C.; Sun, S.; Liu, H.; Yan, P. Development and modeling of an ultrasensitive label-free electrochemical immunosensor for okadaic acid based on polythionine-modified three-dimensional gold nanoelectrode ensembles. Ionics $\mathbf{2 0 2 0}$ 26, 4661-4670. [CrossRef]

19. Blacha-Grzechnik, A.; Piwowar, K.; Zassowski, P.; Motyka, R.; Zak, J. In-situ Raman spectroelectrochemical studies on thionine layer electrochemically grafted to the gold surface. Electrochim. Acta 2017, 245, 902-911. [CrossRef]

20. Chen, Z.; Liu, X.; Liu, D.; Li, F.; Wang, L.; Liu, S. Ultrasensitive Electrochemical DNA Biosensor Fabrication by Coupling an Integral Multifunctional Zirconia-Reduced Graphene Oxide-Thionine Nanocomposite and Exonuclease I-Assisted Cleavage. Front. Chem. 2020, 8, 521. [CrossRef] [PubMed]

21. Zhou, Q.; Li, G.; Zhang, Y.; Zhu, M.; Wan, Y.; Shen, Y. Highly Selective and Sensitive Electrochemical Immunoassay of Cry1C Using Nanobody and $\pi-\pi$ Stacked Graphene Oxide/Thionine Assembly. Anal. Chem. 2016, 88, 9830-9836. [CrossRef]

22. Malard, L.M.; Pimenta, M.A.; Dresselhaus, G.; Dresselhaus, M.S. Raman spectroscopy in graphene. Phys. Rep. 2009, 473, 51-87. [CrossRef]

23. López-Díaz, D.; López Holgado, M.; García-Fierro, J.L.; Velázquez, M.M. Evolution of the Raman Spectrum with the Chemical Composition of Graphene Oxide. J. Phys. Chem. C 2017, 121, 20489-20497. [CrossRef]

24. Bokobza, L.; Bruneel, J.-L.; Couzi, M. Raman spectroscopic investigation of carbon-based materials and their composites. Comparison between carbon nanotubes and carbon black. Chem. Phys. Lett. 2013, 590, 153-159. [CrossRef]

25. de Sousa, T.A.S.L.; Fernandes, T.F.D.; Matos, M.J.S.; Araujo, E.N.D.; Mazzoni, M.S.C.; Neves, B.R.A.; Plentz, F. Thionine Self-Assembled Structures on Graphene: Formation, Organization, and Doping. Langmuir 2018, 34, 6903-6911. [CrossRef] [PubMed]

26. Hutchinson, K.; Hester, R.E.; Albery, W.J.; Hillman, A.R. Raman spectroscopic studies of a thionine-modified electrode. J. Chem. Soc. Faraday Trans. 1984, 80, 2053-2071. [CrossRef]

27. Yu, M.-E.; Cheong, B.-S.; Cho, H.-G. SERS Spectroscopy and DFT Studies of Thionine and its Derivatives Adsorbed on Silver Colloids: Which N Atom is Used for Coordination of a Phenothiazine-Based Natural Dye to Electron-Deficient Metal Surface? Bull. Korean Chem. Soc. 2017, 38, 928-934. [CrossRef]

28. Mažeikienè, R.; Niaura, G.; Eicher-Lorka, O.; Malinauskas, A. Raman spectroelectrochemical study of Toluidine Blue, adsorbed and electropolymerized at a gold electrode. Vib. Spectrosc. 2008, 47, 105-112. [CrossRef]

29. Li, Y.; Yang, W.-K.; Fan, M.-Q.; Liu, A. A Sensitive Label-free Amperometric CEA Immunosensor Based on Graphene-Nafion Nanocomposite Film as an Enhanced Sensing Platform. Anal. Sci. 2011, 27, 727. [CrossRef] 